\section{Physicochemical Properties of a Methacrylate-Based Dental Adhesive Incorporated with Epigallocatechin-3-gallate}

Jiovanne Rabelo Neri ${ }^{1,2}$, Monica Yamauti ${ }^{2}$, Victor Pinheiro Feitosa ${ }^{2}$, Amanda Pontes Maia Pires ${ }^{3}$, Rinaldo dos Santos Araújo ${ }^{3}$, Sérgio Lima Santiago ${ }^{2}$

This study aimed to evaluate the influence of epigallocatechin-3-gallate (EGCG) incorporation on the physicochemical properties of a methacrylate-based dental adhesive. EGCG was added to Adper Easy One (3M-ESPE) except in control group, to obtain concentrations of $0.01 \% \mathrm{w} / \mathrm{w}$ and $0.1 \% \mathrm{w} / \mathrm{w}$ of EGCG-doped adhesives. For water sorption (WS) and solubility (SL) surveys, resin discs were assayed following ISO recommendations $(n=10)$. The degree of conversion (DC) was analyzed by FIR whereas flexural strength (FS) was tested by three-point bending with bar specimens $(n=10)$. Data were subjected to one-way ANOVA and Tukey's test $(p<0.05)$. No significant difference in the DC, WS and FS were found between the different concentrations of EGCG ( $p>0.05)$. Adhesives containing $0.1 \%$ or $0.01 \%$ of EGCC demonstrated similar values of SL $(p>0.05)$ and higher than those found for adhesive without EGCC $(p<0.05)$. In conclusion, the addition of EGCC to adhesive reduced the solubility without affecting the other evaluated properties.

\author{
'Department of Restorative \\ Dentistry, School of Dentistry, \\ UNIFOR - University of Fortaleza, \\ Fortaleza, CE, Brazil \\ ${ }^{2}$ Department of Restorative Dentistry, \\ School of Pharmacy, Dentistry and \\ Nursing, UFC - Federal University \\ of Ceará, Fortaleza, CE, Brazil \\ ${ }^{3}$ Department of Chemistry and \\ Environmental Technology, \\ Federal Institute for Education, \\ Science and Technology of \\ Ceará, Fortaleza, CE, Brazil
}

Correspondence: Dr. Sérgio Lima Santiago, Rua Monsenhor Furtado S/N, 60430-355 Fortaleza, CE, Brasil. Tel: +55-85-8824-2704. e-mail: sergiosantiago@ufc.br

Key Words: mechanical phenomena, dental adhesives, flavonoids.

\section{Introduction}

Dental adhesives have created several alternatives for direct build-ups and other restorative treatments since their introduction more than forty years ago (1). However, their bonding performance on dentin may not be as durable as previously assumed (2). The resin-dentin bonds attained with most of the contemporary adhesives can deteriorate over time $(3,4)$.

A recent review has indicated that the hybrid layer created by the in situ polymerization of resin monomers (generally dimethacrylates) infiltrated in a partially demineralized dentin organic matrix is the weak link in the adhesive restorations (5). Aging may affect most of the components in the resin-dentin interface individually or simultaneously (6). The dentin bond degradation may occur via two mechanisms: 1 . the hydrolytic degradation of the polymer within the hybrid and adhesive layers and 2. the breakdown of the resin-sparse collagen fibrils $(1,2)$. Self-etching of dental substrates without a separate phosphoric acid application reduces the zone of resinsparse collagen (6).

Overall, the self-etch adhesives contain relatively more hydrophilic components since acidic functional monomers and water are needed for a feasible etching of dentin and enamel $(7,8)$. Therefore, these more hydrophilic adhesives tend to rapidly absorb water (7). Water transudation accelerates the swelling, plasticization and the elution of unreacted monomers (9). Furthermore, the accelerated degradation of the collagen by host-derived enzymes (i.e. matrix-metalloproteinases and cathepsins) plays a significant role on the degradation of dentin bonds (10). Thus, both mechanisms could lead to degradation of the dentin bond $(7,10)$, as well as the drop in the physical properties of dental adhesives (11) by the polymer hydrolysis.

Some natural chemicals, such as flavonoids (present in fruits, vegetables, nuts, seeds and flowers) have shown enzymatic inhibition (4) and potential collagen crosslinking (12). Epigallocatechin-3-gallate (EGCG) is the main flavonoid of green tea (Camelia sinensis) and it has been investigated due to its potential against cancer (13). Notably, this polyphenol has demonstrated to be an effective inhibitor of matrix-metalloproteinases (MMPs) and cysteine cathepsins (13). It has been shown that EGCG can increase the collagen cross-linking and prevent the free access of collagenase to the active sites on the collagen chains (14). Recent studies demonstrated the beneficial effects of EGCG mixed in dental adhesive, which maintained resin-dentin bond strength over time $(3,4)$. Nevertheless, the effects of this mixture on the physicochemical properties of self-etch dental adhesives have never been previously evaluated.

The aim of this study was to evaluate the influence of EGCG incorporation on the physicochemical properties of a commercial methacrylate-based dental bonding agent. The tested hypothesis was that different concentrations of EGCG do not cause a detrimental effect on the water sorption/solubility, the degree of conversion and the flexural strength of the adhesive. 


\section{Method and Materials}

Doping the Adhesive with EGCG

A commercial one-step self-etch adhesive, Adper Easy One (EO, also known as Adper Easy Bond; 3M ESPE, St. Paul, MN, USA), was used in this study. EGCG (Sigma Aldrich, St. Louis, MO, USA) was added to the adhesive system in $0.01 \% \mathrm{w} / \mathrm{w}$ (EGCG 0.01 ) or $0.1 \% \mathrm{w} / \mathrm{w}$ (EGCG $0.1)$ concentrations. In order to obtain a homogenous mixture, the EGCG-doped adhesives were shaken using a tube agitator (QL-901; Biomixer, São Paulo, SP, Brazil) in the dark for $1 \mathrm{~min}$. The homogeneity of the dilution was carefully checked and it was used only if no crystals were noted. The three tested adhesive systems (EO - Control, EGCG 0.01 and EGCG 0.1) were evaluated in vitro using water sorption, water solubility, degree of conversion and flexural strength experiments.

\section{Water Sorption/Solubility}

Water sorption and solubility were determined following ISO 4049:2000 except for specimen dimensions, as previously reported (15).

The disc specimens $(n=10)$ were prepared using a Teflon matrix ( $10 \mathrm{~mm}$ diameter and $1 \mathrm{~mm}$ thick). A Mylar strip and a glass slide were placed on the discs after dispensing the adhesive systems using micro-pipettes. The light-activation was undertaken for $40 \mathrm{~s}$ using a halogen lamp light source (VIP junior; Bisco Inc., Schaumburg, IL, USA) with 500 mW/ $\mathrm{cm}^{2}$ irradiance at both sides of each specimen and they were ground and slowly polished to a $0.5-\mathrm{mm}$ thickness using 600-grit SiC polishing papers.

The discs were stored in a silica-containing desiccator at $37{ }^{\circ} \mathrm{C}$ and were repeatedly weighed in $24 \mathrm{~h}$ intervals on an analytical scale (AUX-220; Shimadzu, Tokyo, Japan) with an accuracy of $0.0001 \mathrm{~g}$ until a constant mass (m1) was obtained (i.e.,variation less than $0.1 \mathrm{mg}$ in three consecutive weight measures). The volume of each specimen was calculated with a $0.001 \mathrm{~mm}$ precision digital caliper (Absolute Digimatic; Mitutoyo, Tokyo, Japan) to measure the diameter and thickness, and the volume (V) was expressed in $\mathrm{mm}^{3}$. Next, the specimens were stored in sealed glass vials with $10 \mathrm{~mL}$ of distilled water at $37{ }^{\circ} \mathrm{C}$ for 7 days. Afterwards, the specimens were weighed after gently wiped on absorbent papers to obtain a constant mass $\left(\mathrm{m}_{2}\right)$ and then they were returned to the desiccator. The specimens were finally weighed as aforementioned up to stabilization of mass $\left(\mathrm{m}_{3}\right)$. Water sorption (WS) and solubility (SL) ( $\mu \mathrm{g} /$ $\mathrm{mm}^{3}$ ) were calculated using the following formulae:

$$
W S=(m 2-m 3) / N \quad S L=(m 1-m 3) / N
$$

The data were statistically analyzed using one-way ANOVA and Tukey's test $(p<0.05)$.

\section{Degree of Conversion}

The degree of conversion (DC) of the adhesive resins was assessed by Fourier Transform Infrared Spectroscopy (FIR) (Perkin-Elmer Spectrum 100; Perkin Elmer, Shelton, CT, USA). Each adhesive system was dispensed into a small agate mortar and thoroughly mixed with potassium bromide $(\mathrm{KBr})$ using a pestle, at a ratio of 4:100. The pellets of $\mathrm{KBr} / \mathrm{adh}$ esive solution were prepared with a hand press (Hand Press Kit 161-1100; PIKE Technologies, Madison, WI, USA). FIIR spectrum of the uncured adhesive was obtained from each sample using 32 scans in a range of 4000-400 $\mathrm{cm}^{-1}$ at $4 \mathrm{~cm}^{-1}$ resolution in transmission mode.

The adhesive resins were light activated for $20 \mathrm{~s}$ using the light source (VIP junior, Bisco Inc.). The other FIR spectra were obtained immediately after light curing. The analyses were performed at room temperature with $50 \%$ relative humidity. Ten specimens per group $(n=10)$ were tested. The rate of unreacted carbon-carbon double bonds $(\mathrm{C}=\mathrm{C})$ was determined from the ratio of absorbance intensities of aliphatic $\mathrm{C}=\mathrm{C}$ (peak at $1636 \mathrm{~cm}^{-1}$ ) against an internal standard (aromatic carbon-carbon bond peak at $1608 \mathrm{~cm}^{-1}$ ) before and after curing. Degree of conversion was determined by subtracting the $\mathrm{C}=\mathrm{C}$ from $100 \%$. Data were statistically analyzed using one-way ANOVA and Tukey's test $(\mathrm{p}<0.05)$.

\section{Flexural Strength}

A three-point bending test was used to assess the flexural strength (FS) of bar-shaped specimens. Twenty microliters of each adhesive resin was placed into a Teflon matrix to prepare the bar-shaped specimens $(25 \mathrm{~mm}$ long $\times 2 \mathrm{~mm}$ wide $\times 2 \mathrm{~mm}$ high) according to ISO 4049:2000 standard. The adhesive resins were air-dried for $20 \mathrm{~s}$ for solvent evaporation. Before the light-activation, a Mylar strip was placed on the top of the matrix and covered with a glass slide.

The adhesives were light-activated for $40 \mathrm{~s}$ with the light source (VIP junior, Bisco Inc.) at 3 different positions (right, middle and left) of sample. After light activation, the specimens were removed from the matrix, and the bottom surface was additionally light-activated for 40 s. Specimens were stored for $24 \mathrm{~h}$ in distilled water at $37^{\circ} \mathrm{C}$ and subjected to a three-point bending test using a universal testing machine (Instron 3345; Instron Corp., Canton, MA, USA) at a crosshead speed of $1.0 \mathrm{~mm} / \mathrm{min}$. The dimensions of each specimen were measured using a digital caliper (0.01 mm precision, Absolute Digimatic; Mitutoyo). The FS was calculated and transformed to MPa according to the formula:

$$
\mathrm{FS}=3 \mathrm{FI} /\left(2 w b^{2}\right)
$$

Where $F=$ maximum force $(\mathrm{N})$ at fracture; $\mathrm{I}=$ the distance 
between the supports (fixed at $20 \mathrm{~mm}$ ), $\mathrm{w}=$ specimen width; and $b=$ specimen thickness.

Data were statistically analyzed using one-way ANOVA and Tukey's test $(p<0.05)$.

\section{Results}

The results of the study are presented in Table 1. There was no significant difference in the WS among all groups $(p=0.158)$. On the other hand, the SL outcomes were significantly different $(p<0.001)$ presenting reduced solubility by increasing the EGCG concentration.

The degree of conversion was significantly similar among all tested adhesive resins $(p=0.214)$. There were no significant differences in the FS values among all groups $(p=0.313)$.

\section{Discussion}

The main active component of green tea is EGCG. It has shown several outstanding therapeutic effects on oral health (16). Two principal properties of EGCG related to restorative/conservative dentistry are its bacteriostatic activity (17) on Streptococcus mutans, one of the main bacteria responsible for the progress of dental caries, and its MMP inhibition potential, which strikingly prevents dentin collagen degradation (18). Furthermore, dentin treatment using EGCG significantly improved (19) the mechanical properties of demineralized dentin, which suggests potential collagen cross-linking. Previous investigations also demonstrated the action of EGCG in very low concentrations $(3,17)$. Therefore, the very low concentrations of EGCG as used in the present study might be suitable to attain its potential therapeutic effects.

Water sorption of dental polymers may be positively correlated with the hydrophilicity of the overall components $(7-9,15)$. Most dental methacrylate-based monomers as well as photoinitiators contain polar functionalities such as esters and hydroxyls (20). The polarity of adhesive systems influences their affinity with water molecules (8). Though EGCG is a relatively polar molecule due to several hydroxyls $(21,22)$, no increase in the water sorption was attained in EGCG-doped adhesives (Table 1). Pallan et al. (23) showed that the water sorption of different resins was associated with their formulations (hydrophilic components/ features) instead of the presence of EGCG. Indeed, the low concentrations of EGCG $(0.01 \%$ and $0.1 \%)$ in the present investigation were not able to cause a significant increase in the overall hydrophilicity of the one-step self-etch adhesive, which could result in significantly increased water sorption.

Simplified adhesives (i.e. one-step self-etch adhesives) often exhibit relatively high water sorption and solubility $(9,15)$. High solubility was also found when EGCG $(1 \mathrm{wt} \%$ and $2 \mathrm{wt} \%$ ) was incorporated to adhesive resins (23). It was speculated that the increase in solubility of EGCG-doped resins occurs due to the release of EGCG along with residual monomers and oligomers. Conversely, in the present study incorporation of EGCG $(0.01 \%$ and $0.1 \%)$ reduced the $\mathrm{SL}$ of the tested resin. Such outcome may be explained by the difficult achievement of a homogeneous mixture between the branched catechin (EGCG) molecule and the polymer network. Potential hydrogen bonds between the EGCG hydroxyls, HEMA and Bis-GMA (23) are also feasible linkages, which could impair the release of components resulting in lower solubility.

The degree of conversion is a useful strategy to assess the basic physicochemical properties of a dental resin, such as maximum polymerization reaction (24). The present findings demonstrated that the incorporation of EGCG in low concentrations into a specific one-step self-etch adhesive did not cause any negative effect on the DC (Table 1). These results are corroborated by recent studies $(3,23)$. Du et al. (3) speculated that high EGCG concentrations (more than 0.3\%) could induce the formation of linear polymer chains, and the free radical scavenging effect of EGCG may jeopardize the polymerization. Indeed, the low concentrations of EGCG may have avoided these phenomena without interfering with polymerization conversion.

The final conversion after light curing affects several mechanical properties such as the flexural strength (24). Nevertheless, polymers with similar degree of conversion may exhibit different crosslink densities, which may afford contrasting flexural strengths (25). Since EGCG incorporation did not affect the FS (Table 1), it may be assumed that the cross-linking of the tested resins is similar. In fact, the same cross-linking of the polymer matrix plays

Table 1. Mean (95\% confidence intervals) of the tested physicochemical properties

\begin{tabular}{lcccc}
\hline Groups $(\mathrm{n}=10)$ & Water Sorption $\left(\mathrm{mg} / \mathrm{mm}^{3}\right)$ & Solubility $\left(\mathrm{mg} / \mathrm{mm}^{3}\right)$ & Degree of conversion \% & Flexural Strength $(\mathrm{MPa})$ \\
\hline EO (Control) & $180.2(175.1-185.3)$ & $82.4(79.3-85.5)^{\mathrm{a}}$ & $68.5(66.5-70,1)$ & $18.7(15.6-21.8)$ \\
EGCG $0.01 \% \mathrm{w} / \mathrm{w}$ & $173.9(165.3-182.5)$ & $59.7(53.3-66.1)^{\mathrm{b}}$ & $69.4(67.5-71.3)$ & $16.0(13.9-18.1)$ \\
EGCG $0.1 \% \mathrm{w} / \mathrm{w}$ & $180.0(173.8-186.2)$ & $62.9(57.5-68.3)^{\mathrm{b}}$ & $70.6(68.6-72.6)$ & $18.5(14.8-22.2)$ \\
\hline Distinct superscript letters indicate statistically significant difference in the same column $(\mathrm{p}<0.05)$. &
\end{tabular}


an important role on the similarity in water sorption among all concentrations of EGCG.

The observed results showed that the incorporation of EGCG into Adper Easy One, a one-step self-etch adhesive, did not affect its physicochemical properties, except the solubility. This leads to a partial acceptance of the hypothesis. A limitation of this study was not quantifying the release of EGCG from the adhesive system. Therefore, further studies are encouraged to assess the releasing of EGCG in order to inhibit proteinases and improve the resin-dentin bonds over time.

In conclusion, EGCG incorporation (0.01\% and 0.1\%) into a self-etch dental adhesive may be useful for therapeutic adhesion to dental hard substrates, particularly to dentin, due to the potential of improving the longevity of adhesive procedures.

\section{Resumo}

Esse estudo teve como objetivo avaliar a influência da incorporação de epigalocatequina-3-galato (EGCG) nas propriedades fisico-quimicas de um sistema adesivo à base de metacrilato. 0 EGCG foi adicionado ao Adper Easy One (3M-ESPE), exceto para o grupo controle, para a obtenção das concentrações de $0,01 \%$ e 0,1\% p/p. No ensaio de sorção (S) e solubilidade (SL), foram confeccionados discos de resina de acordo com as recomendações da ISO $(n=10)$. 0 grau de conversão (GC) foi analisado através de FIIR, enquanto a resistência flexural (RF) foi avaliada em teste de flexão de três pontos com espécimes em forma de barra $(n=10)$. Os dados foram submetidos à Análise de Variância a um critério e teste de Tukey $(p<0,05)$. Não houve diferença significativa entre as concentrações de EGCG testadas no GC, SL e RF $(p>0,05)$. Adesivos contendo EGCG a 0,1\% ou $0,01 \%$ apresentaram valores similares de $S L(p>0,05)$ e maiores do que os valores obtidos pelo adesivo não incorporado por EGCG. Conclui-se que a adição de EGCG ao adesivo reduziu a solubilidade sem afetar as outras propriedades avaliadas.

\section{References}

1. Breschi L, Cammelli F, Visintini E, Mazzoni A, Vita F, Carrilho M, et al.. Influence of chlorhexidine concentration on the durability of etchand-rinse dentin bonds: A 12-month in vitro study. J Adhes Dent 2009;11:191-198.

2. Hebling J, Pashley DH, Tjaderhane L, Tay FR. Chlorhexidine arrests subclinical degradation of dentin hybrid layers in vivo. J Dent Res 2005;84:741-746.

3. Du $X$, Huang $X$, Huang $C$, Wang $Y$, Zhang Y. Epigallocatechin-3-gallate (EGCG) enhances the therapeutic activity of a dental adhesive. J Dent 2012;40:485-492.

4. Santiago SL, Osorio R, Neri JR, Carvalho RM, Toledano M. Effect of the flavonoid epigallocatechin-3-gallate on resin-dentin bond strength. J Adhes Dent 2013;15:535-540.

5. Spencer P, Ye Q, Park J, Topp EM, Misra A, Marangos O, et al.. Adhesive/ dentin interface: the weak link in the composite restoration. Ann Biomed Eng 2010;38:1989-2003.

6. Breschi L, Mazzoni A, Rugger A, Cadenaro M, di Lenarda R, de Stefano DE. Dental adhesion review: Aging and stability of the bonded interface. Dent Mater 2008;24:90-101.
7. Malacarne J, Carvalho RM, de Goes MF, Svizero N, Pashley DH, Tay FR, et al.. Water sorption/solubility of dental adhesive resins. Dent Mater 2006;22:973-980.

8. Yiu CK, King NM, Carrilho MR, Sauro S, Rueggeberg FA, Prati C, et al.. Effect of resin hydrophilicity and temperature on water sorption of dental adhesive resins. Biomaterials 2006;27:1695-1703.

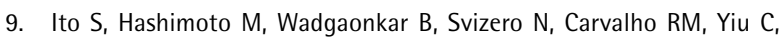
Rueggeberg FA, et al.. Effects of resin hydrophilicity on water sorption and changes in modulus of elasticity. Biomaterials 2005;26:6449-6459.

10. Tjäderhane L, Nascimento $F D$, Breschi L, Mazzoni A, Tersariol IL, Geraldeli $\mathrm{S}$, et al.. Optimizing dentin bond durability: Control of collagen degradation by matrix metalloproteinases and cysteine cathepsins. Dent Mater 2013;29:116-135.

11. Hosaka K, Tagami J, Nishitani Y, Yoshiyama M, Carrilho M, Tay FR, et.al.. Effect of wet vs. dry testing on the mechanical properties of hydrophilic self etching primer. Eur J Oral Sci 2007;115:239-245.

12. Bedran-Russo AK, Pereira PN, Duarte WR, Drummond JL, Yamauchi M. Application of crosslinkers to dentin collagen enhances the ultimate tensile strength. J Biomed Mater Res B Appl Biomater 2007;80:268272.

13. Garbisa S, Sartor L, Biggin, S. Salvato, B, Benelli, R, Albini A. Tumor gelatinases and invasion inhibited by the green tea flavanol epigallocatechin-3-gallate. Cancer 2001;91:822-832.

14. Jackson JK, Zhao J, Wong W, Burt HM. The inhibition of collagenase induced degradation of collagen by the galloyl-containing polyphenols tannic acid, epigallocatechingallate and epicatechingallate. J Mater Sci Mater Med 2010;21:1435-1443.

15. Ito $\mathrm{S}$, Hoshino T, lijima M, Tsukamoto N, Pashley DH, Saito T. Water sorption/solubility of self-etching dentin bonding agents. Dent Mater 2010;26:617-626.

16. Narotzki $B$, Reznick $A Z$, Aizenbud D, Levy $Y$. Green tea: a promising natural product in oral health. Arch Oral Biol 2012;57:429-435.

17. Mankovskaia $A$, Lévesque $C M$, Prakki A. Catechin-incorporated dental copolymers inhibit growth of Streptococcus mutans. J Appl Oral Sci 2013;21:203-207.

18. Kato MT, Leite AL, Hannas AR, Calabria MP, Magalhães AC, Pereira JC, et al.. Impact of protease inhibitors on dentin matrix degradation by collagenase. J Dent Res 2012;91:1119-1123.

19. Hiraishi, N., Sono, R., Sofiqul, I., Yiu, C., Nakamura, H., Otsuki, M., et.al.. In vitro evaluation of plant-derived agents to preserve dentin collagen. Dent Mater 2013;29:1048-1054.

20. Ferracane JL. Hygroscopic and hydrolytic effects in dental polymer networks. Dent Mater 2006;22:211-222.

21. Kim WJ, Kim JD, Kim J, Oh SG, Lee YW. Selective caffeine removal from green tea using supercritical carbon dioxide extraction. J Food Eng 2008;89:303-309.

22. Lambert JD, Sang S, Hong J, Kwon SJ, Lee MJ, Ho CT, et al.. Peracetylation as a means of enhancing in vitro bioactivity and bioavailability of epigallocatechin-3-gallate. Drug Metab Dispos 2006;34:2111-2116.

23. Pallan S, Furtado Araujo MV, Cilli R, Prakki A. Mechanical properties and characteristics of developmental copolymers incorporating catechin or chlorhexidine. Dent Mater 2012;28:687-694.

24. Arrais CA, Pontes FM, Santos LP, Leite ER, Giannini M. Degree of conversion of adhesive systems light-cured by LED and halogen light. Braz Dent J 2007;18:54-59.

25. Ferracane JL. Correlation between hardness and degree of conversion during the setting reaction of unfilled dental restorative resins. Dent Mater 1985;1:11-14. 